Session 3666

\title{
Teaching Dynamics Online with only Electronic Media on Laptop Computers
}

\author{
Yellamraju Vikas, Tony Romanello and Kurt Gramoll \\ Aerospace and Mechanical Engineering \\ University of Oklahoma
}

\begin{abstract}
The benefits of electronic media in engineering, such as interactive simulations, threedimensional visualization and animations are widely known. However the implementation of such media has been difficult because of lack of classroom facilities and student access to the programs. Most of the implementation problems can be overcome and a true asynchronous learning environment can be established if $\mathrm{CD}$ based multimedia is integrated with current course material on the Internet. This scenario is particularly useful when all students have their own personal laptop computers and the learning environment is connected with a wireless network. This paper will demonstrate and discuss the experiences at the University of Oklahoma, where the basic Dynamics class was taught using laptop computers, CD-ROMs, and the Internet.

This project did not develop new courseware, but instead used the Multimedia Engineering Dynamics CD-ROM (published by Gram Media, 1999) for the main course content. The CD was however supplemented with newly developed intranet-based material such as electronic homework, examples, quizzes, solutions, and lectures. The outcome of the course showed that students could use distance-learning methods to enhance their learning on a university campus. Some of the benefits included instant access to all course material, quick feedback of homework and quizzes, and on-demand course lectures. The course has been taught one semester, and is being used at $\mathrm{OU}$ as the foundation for future engineering courses that can be delivered via the Internet. The course can also serve as a test bed for future use of electronically delivered courses for engineering students who cannot attend classes due to disabilities, schedule conflicts or geographic distance. The paper also explores the methods used to develop the course and what software tools were used to implement the computer-based learning environment.
\end{abstract}




\section{Introduction}

The most promising feature of multimedia and network-based media is its ability to interactively display complex information or concepts in an accessible and easy-to-understand animated graphical form. This is obviously well suited for many educational applications, but it is particularly attractive for use in engineering education where abstract mathematical models and fundamental physical principles must be employed to solve practical problems. One of the more difficult issues to deal with in the engineering curriculum, especially at the introductory levels, is this process of abstraction of real and practical situations into mathematical models. The engineering curriculum is filled with analysis courses where the focus is invariably on the analysis of completely determined homework problems that represent some implied abstraction from reality (and for which a "unique" answer is available in the back of the book).

Furthermore, intuition is a vital component of human decision-making, and it is no less so in engineering problem solving. Given the rapid development of technology, the curriculum is under continual compaction as new topics are added and older material is edged out to maintain a nominal 4-year program. One of the earliest casualties in this process has been the application of engineering principles to practical problems through the mechanism of realistic homework problems, homework sessions, tutorial sessions, project labs, and the like. The result is having engineering graduates with impressive analytical skills, but with little or no understanding of how to apply these skills in an effective manner to solve problems. Multimedia and network based media technologies have the potential of providing a mean for dealing with these issues in a dynamic, provocative and likely cost-effective manner that not only will increase the effectiveness of the educational program but will also increase the quality of the resulting students $[1,2]$.

However, electronic media has it own set of problems and difficulties. First, the structure of the system must be determined. In the case of this course, if server-based CGI-Perl scripting is going to be used, then the programming of the problem database, and online homework management must be developed. Foremost is the time and effort needed to develop and implement electronic media. Similar to authoring a textbook, the core material will take 1-2 years to develop. Next the weekly material, such as homework and quizzes needs to be added to web pages in electronic form. This is not just simply scanning problems from existing notes or old tests, but constructing them from scratch using a drawing program. Other types of media can also be added to the web site, such as lectures and discussion groups. The lectures are digitized video of the actual class lecture and this process is not as simple as running them through a computer. A number of important factors must be met in order for a high quality video with useful content to be produced, which is outlined in later sections. Also, discussion groups using electronic bulletin boards are used to allow students, teaching assistants and instructors to post and answer questions during normal working hours and in the evenings. Finally, there is the need to have online quizzes and tests. Strictly speaking, online tests are not necessary for courses on campus, but it is expected that by the following semester this course will be offered to students at remote sites that cannot attend class. Thus, all material, including quizzes and tests are made available in electronic form. 
The primary purpose of this paper will focus on examining all the different types of electronic media used in the Dynamics course. All of the electronic media was accessed through the main Dynamics course web page (Fig. 1) except the basic course theory and examples that were made available separately on the course CD-ROM. This paper will give the reader a complete overview of a typical online course used for students on and off the campus, without the option of a classroom, and traditional teaching methods. The paper will address five main parts of the online course and its content namely, lectures, discussion groups, online course management, quizzes, and homework. General course information, such as syllabus, is not discussed since it is assumed that all courses have this basic information posted for all courses.

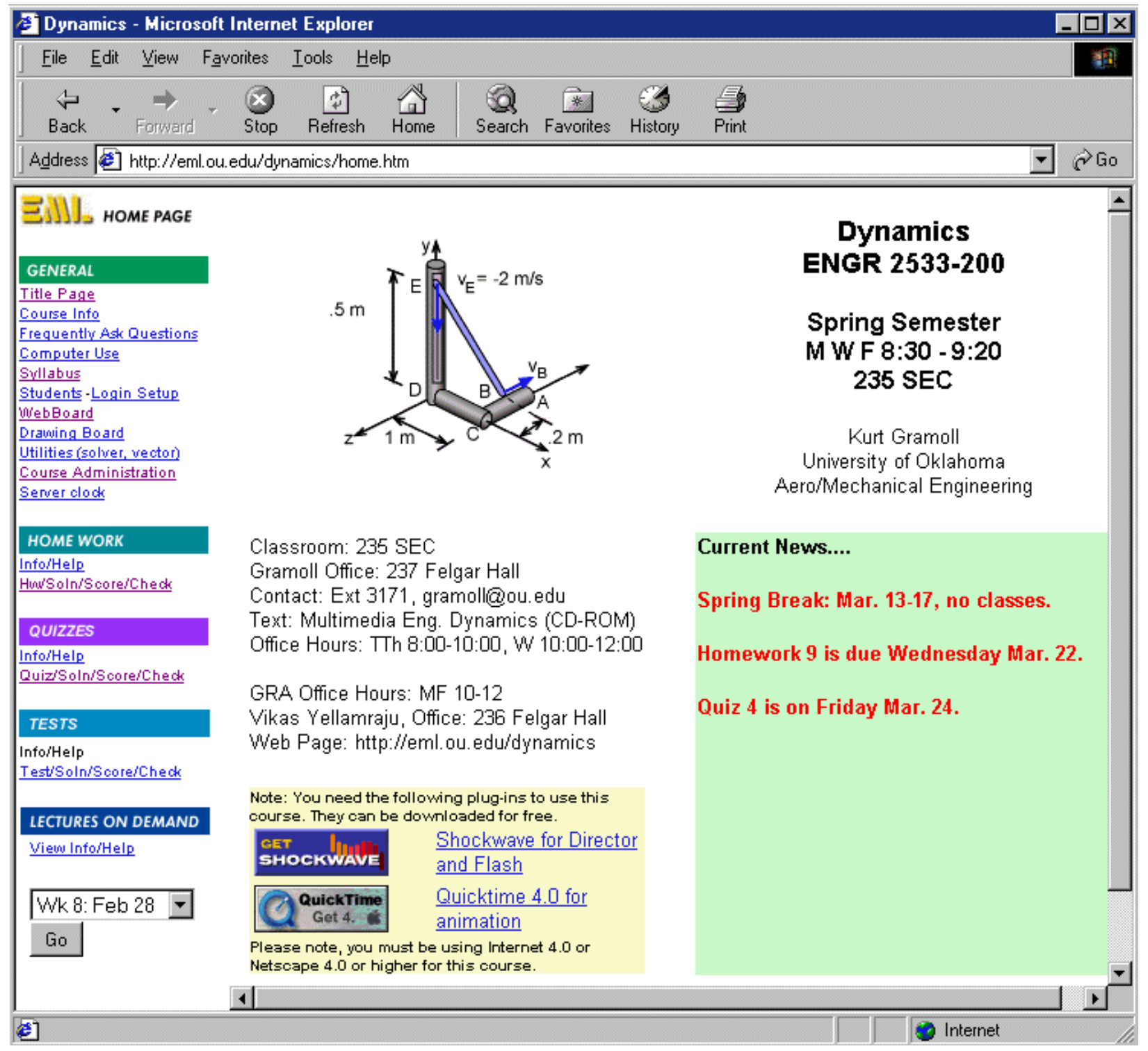

Fig. 1. Web Site main page 


\section{CD-Based courseware}

Although the web site had homework, quizzes, tests, syllabus, utilities, and lectures-on-demand, the students still needed the core theory and examples. For this course, the theory and examples were delivered to the student on a CD-ROM that was developed by the author three years earlier $[3,4]$. The CD-ROM, which was presented in a case study approach, contained all theory for the Dynamics course. Each major topic was introduced through the use of a typical engineering problem. Each case was fully worked out and supported by the appropriate theory. Case-based learning has a number of benefits, such as the ability to hold a student's attention and provide an application for abstract fundamental concepts [5].

The Dynamics CD-ROM contains a total of 42 cases, each illustrating a specific concept in Dynamics. Each case or example is presented in four parts: Introduction, Theory, Solution, and Simulation. Each part incorporates graphics, audio components, animations, videos, and hypertext. The first part introduces a problem to the user. The second part presents specific Dynamics concepts that are required to solve the problem (Fig. 2). The third part actually walks through the solution. The fourth part allows the student to experiment with a computergenerated simulation that explores the parameters of the problem. Reference materials for engineering Dynamics are also accessible through the appendices.

Due to the large amount of material on the CD-ROM, it was not possible to place it on the web because the download times for the animations were too large. However, by making the main course content available on the $\mathrm{CD}$, the students were able to access the course material even if they were not connected to the Internet. The CD served the same purpose in the course as a textbook in a traditional classroom oriented course in that it presented the main source of theory and examples. However, the CD was not used extensively in the course lectures since it was expected that the students would review and use the material on their own, as they would a textbook. The purpose of the lecture was not to simply show CD content, but to explain the concepts from a different viewpoint. This allowed the students to have another perspective on the theory and problem solving process. 


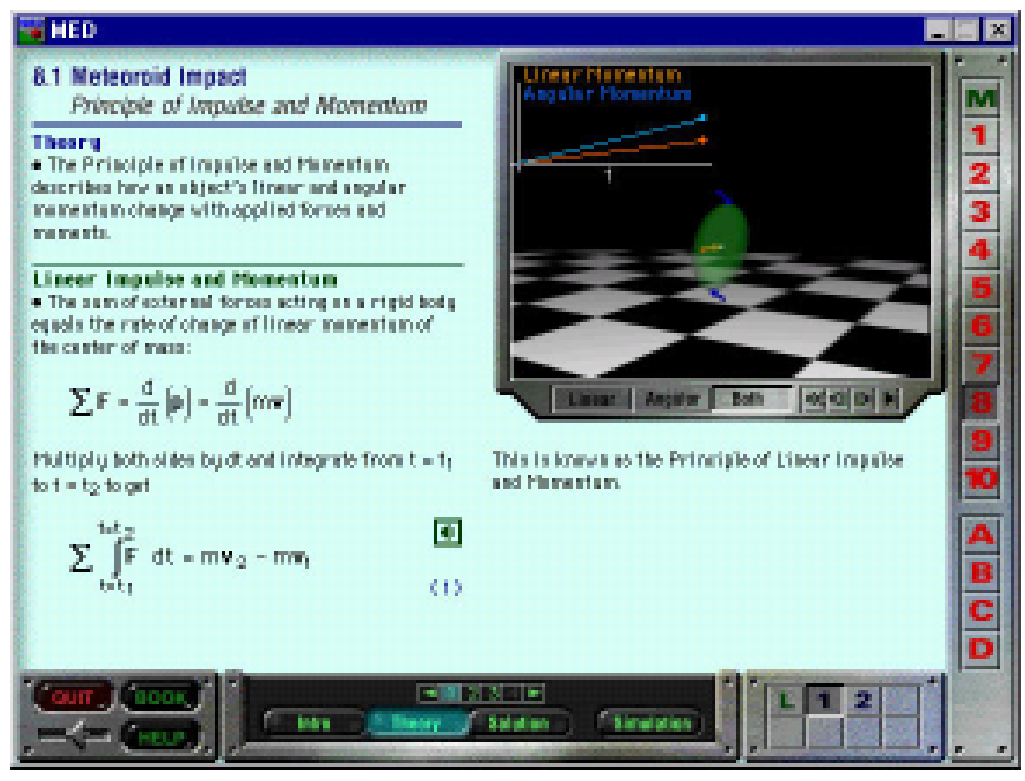

Fig. 2. Typical theory page from the Dynamics CD-ROM.

\section{Online Course Management, Homework, Quizzes and Tests}

An important benefit in the use of electronic media for a course is the convenience of access to course materials from a CD and to homework solutions over the Internet. This also allows the Instructor and the Teaching Assistant to have virtual office hours to monitor student needs. In addition to the course content being delivered electronically via a CD-ROM, the homework and quizzes were designed and delivered in an electronic format over the Internet. Electronic-based homework and quizzes that are graded automatically by the system required all questions to be either 'fill-in-the-blank' or multiple-choice. Changing the answer selection process to this format was the single most difficult change that the author had to encounter in implementing an allelectronic course. Traditionally, partial credit is given to students in engineering courses due to the difficulty in solving problems and frequency of simple errors such as algebra and sign errors. Even though partial credit is not possible with fill-in-the-blank or multiple-choice questions, an instructor can minimize the effects of its absence by asking more questions and directing each question to deal with only a single concept or step. In order to do so, the instructor is then burdened to develop new homework, quizzes and tests that fit such a style. However, this process does allow for better monitoring of problems developed using multiple-choice questions. This model also correlates with the various testing methods used outside the university, such as the professional engineering exams.

\section{Quizzes and Tests}

Each problem had to be developed and constructed in electronic form. This involved a regimented process of deriving a question, creating diagrams, transferring the problem and solution to HTML format, and adding various system manipulations. The problem also had to be original in order to avoid copyright infringements with current textbooks. The respective 
problem and solution was then developed in electronic form so that it could be posted on the web after the test or assignment was completed.

Initially, all problems were fill-in the blank but this required manual grading which eliminated some of the advantages of an online course since the students could not get immediate feedback and increased the instructor's time devoted to the course. The decision to use only multiplechoice increased the initial developing time for the problems, but made grading easier. It also paved the way for automated problem generation and grading. Wrong solutions were developed to closely match possible mistakes that the students would make. However, the correct answer was always one of the choices listed, so that the student had the opportunity to work toward the correct answer. Over the course of one semester, over 200 problems were electronically developed with the intent of being web-based.

A typical quiz was 30 minutes long and had four to five problems (Fig. 3). The quizzes were open notes and open computers. Subsequently, the quizzes were modeled after the fundamentals in engineering exam that most undergraduate students take just before their graduation. The students generally finished the quiz within the time allotted, but there was little time to study or attempt to get help online during the actual quiz time. The goal of the quiz was to force the student to quickly set up the problem and obtain a solution. The time pressure to complete the questions quickly was offset by the basic nature of the problems. A timer, programmed in Perl, allowed for an accurate and standard timing device for all the users involved.

The web site to time and allow submission of multiple-choice questions was developed especially for the class by the authors. The site took advantage of JavaScript and CGI-scripting (Perl) to pull problems from the database, set up the answer form and then let the students submit the quiz. The answers were posted after the completion of the quiz. During the quiz, the students could retrieve their submissions to verify that the quiz was submitted correctly. This was an important feature, allowing the students to have the responsibility to make sure their quiz was completed and submitted correctly. If there were a problem, the student would be aware of it and could notify the instructor without waiting until the time for quiz is over. With this checking capability, the problem could then be fixed before the end of the quiz. A similar pattern was followed for tests. 


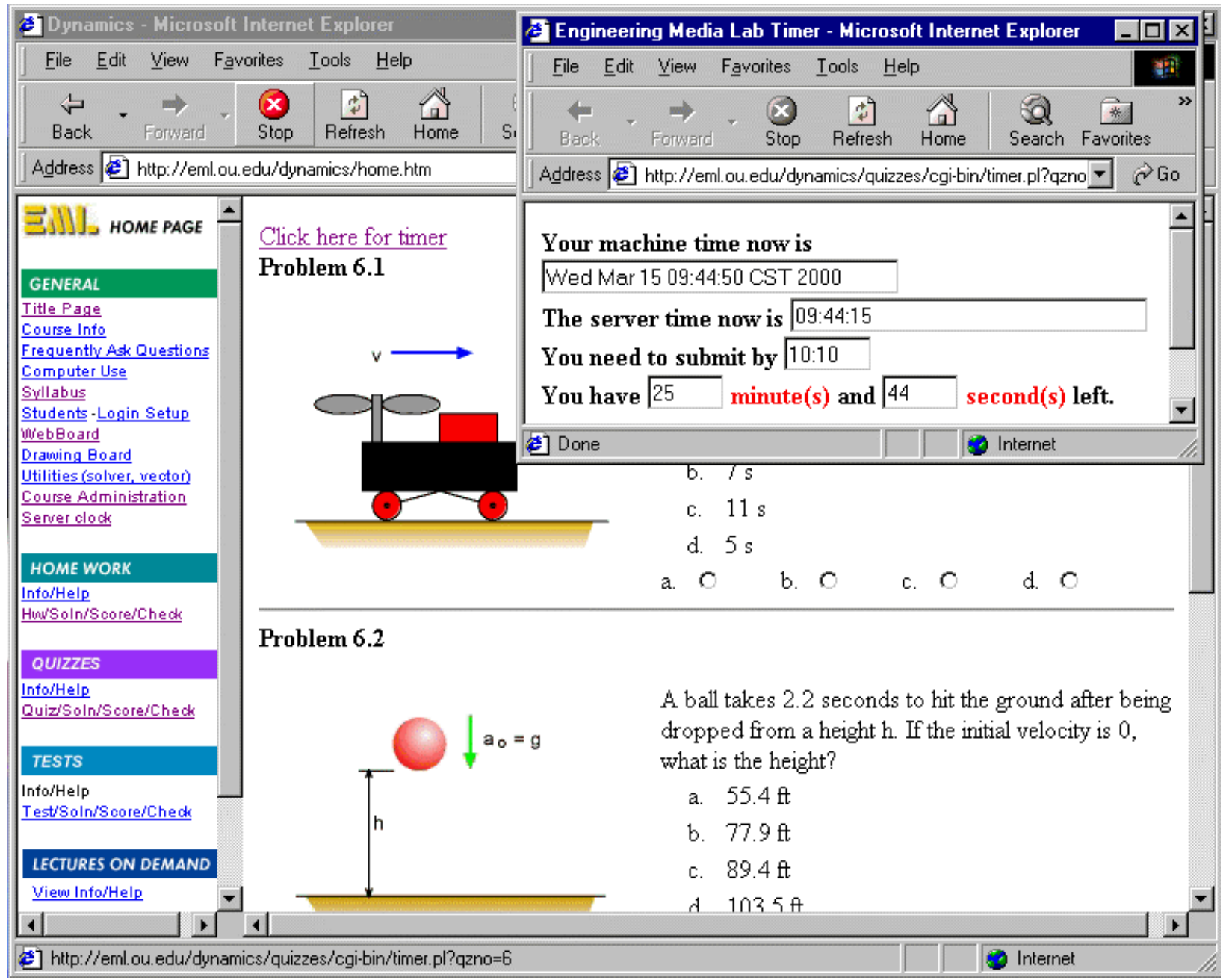

Fig. 3. Typical quiz screen from the web site

Homework, and Online Course Management

All homework was assigned, completed, turned-in, graded, and returned through the Internet. For both homework and quizzes, the instructor had the ability to choose the problems to be assigned via an Internet web page. This allowed the instructor to manage the course onsite and opened the possibility of other instructor at different schools to use the system. The chosen homework was assigned through an organized web page distinguished by sections. For each section, the homework was posted on a secured web page where students were required to log in using their personal ID and password (this ID and password was used for all student records in the class).

The students viewed the homework problems, which included a picture, problem statement, and 4 multiple-choice answers. When the homework was completed the student submitted the answers to the homework through the Internet. The web site not only received the information sent by the student but also recorded the time and date of the submission so late submissions 
could be tracked. Through the use of CGI scripts, the students could check their submission and grades.

For the homework, all diagrams were drawn using Macromedia Freehand and then saved as GIF files for posting to the web site. The graphics were generally simplified when compared to typical textbook graphics due to the reduced 'dots-per-inch' resolution of the computer screen as compared to print media. However, the difference had little effect on the understanding of the problem.

The system automatically graded and posted the results of the homework. The student could then view the results of completed homework. The solution posted on the web had the problem information, a solution graphic, and the solution procedure with the answer. The students generally appreciated the web-based homework solution because it allowed them to view older homework and study for tests and quizzes without having to contact the instructor for solutions or visit a physical bulletin board for posted answers. It was interesting to note that the homework solutions were accessed most heavily between 11 PM to 2 AM the day before a quiz or test.

A key feature to this course was the homework management system that was built using CGI scripts (Perl programming language). Through this Internet-based system, the instructor sets up a course account through a web page. The instructor then adds all students that will have permission to take the course and assign them a user account and password. This is required to insure only real student have access to the homework, solution and tests. When entering the Course Management Link, the instructor enters his own unique instructor ID and password that was previously assigned to him by the system administrator. The instructor can then manage all student accounts, homework, and quiz data, as well as timetables for lectures through a secure and easy to use web page. Furthermore, inside the Course Management Question section, under Homework, Manage Question, the instructor has the ability to choose from a database of over 200 problems for the homework sets (Fig. 4). This gives the instructor the flexibility over those problems that are needed for that class since each class can have different problems. Other features of homework management system included homework set editing, viewing of homework solutions, score distributions, editing of homework schedules, renaming specific homework sets, viewing notes for particular homework, viewing the entire homework database and deleting homework sets.

Another aid was the automatic homework and quiz check. All grades were automatically recorded and securely registered within the system database for each respective student in each respective course, saving instructor time. Grading was done utilizing CGI scripts, so students could receive quick access. The students were assured confidentiality through their respective login ID and password. 


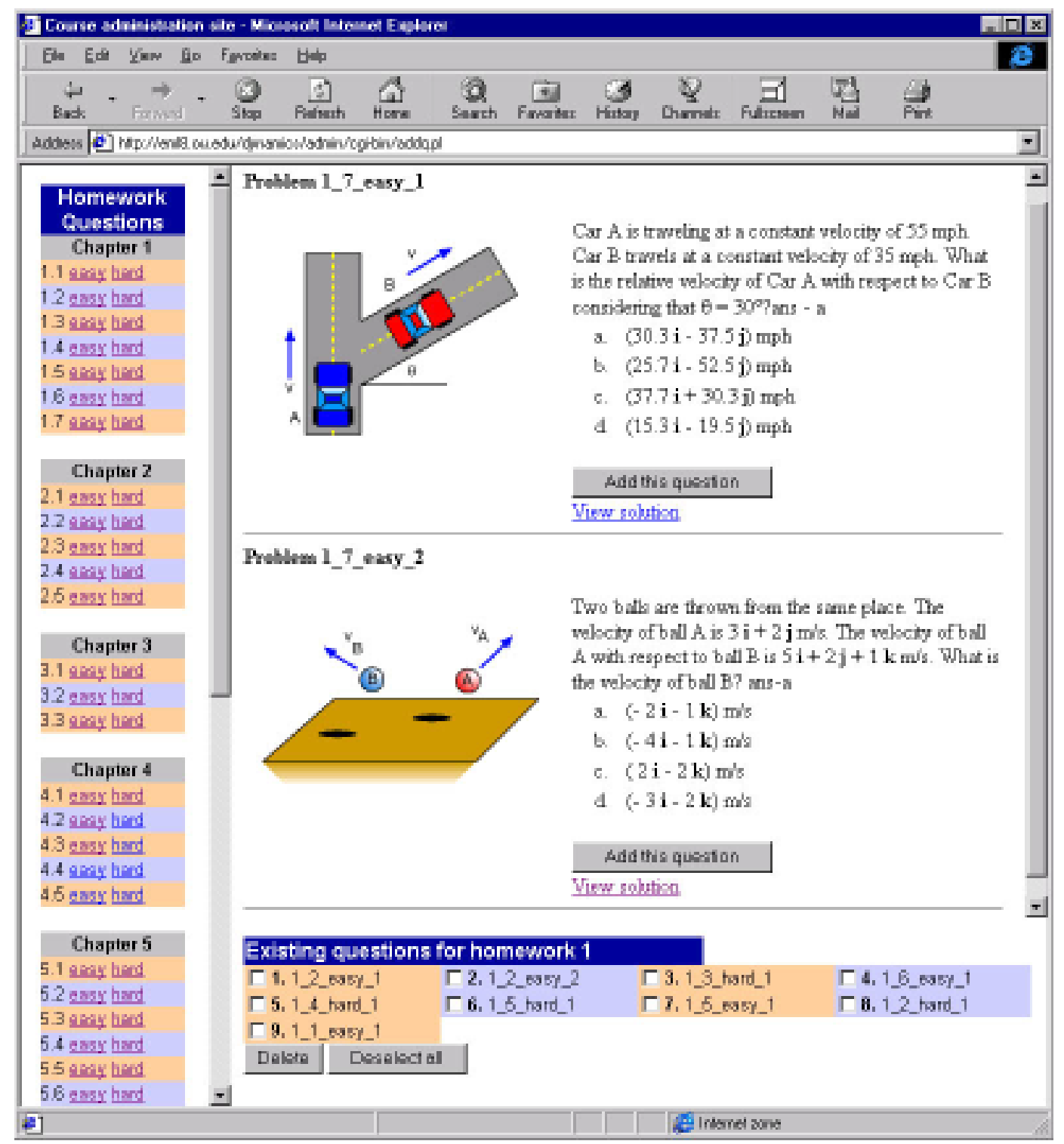

Fig. 4. An example of the online problem selection page for homework

\section{CGI-Perl Scripting}

The entire on-line system took advantage of CGI (Common Gateway Interface) scripting which is a server-based means of transferring data between a server and a client. In this system, Perl programming language was used for the CGI scripts. Perl is an interpreted language mainly used for managing specified text files, taking information from those text files, and printing reports. Perl scripts allow the user to submit data via a homework, quiz, or test page to be processed on the server. The processed results were then posted through Perl scripts back to the client.

A complex backbone of Perl scripts allowed for the system's interaction with the user and the system database. Perl scripts were responsible for the entire management of the database homework system from which the instructor chooses which problems to assign. For the course, 
Perl scripts "dynamically" created the respective web pages. That is, the Perl scripts actually constructed and displayed the respective web pages through code rather than through links to existing HTML documents. This was valuable not only to ensure grade confidentiality, but also to protect the security of the upcoming homework and quizzes, as well as the integrity of the system as a whole.

\section{Discussions Online}

Since most students were not in the physical classroom for the Dynamics course, it was important to have an online discussion method where students could ask questions and get a response. Several solutions were considered, such as email, Internet news groups or web serverbased bulletin boards. The email option had a deficiency similar to normal office hours, in that the same question would probably be answered numerous times. With news groups or bulletin boards, the question is answered once and then all others can view it, thus saving time for both the students and professor. For this course, a commercial program called Web Board (distributed by O'Reilly Publ.) was used for the discussion groups for a number of reasons. A typical web page using Web Board is shown in Fig. 5. This application was operated and controlled on the course server and therefore outside users could be restricted. The program also monitored how many times a student used the discussion group and let other users know how many times the question and answer had been viewed. It was also easy to set up and run completely within a web page, eliminating the need for additional software or browser plug-ins. The program also allowed login and password restriction if needed.

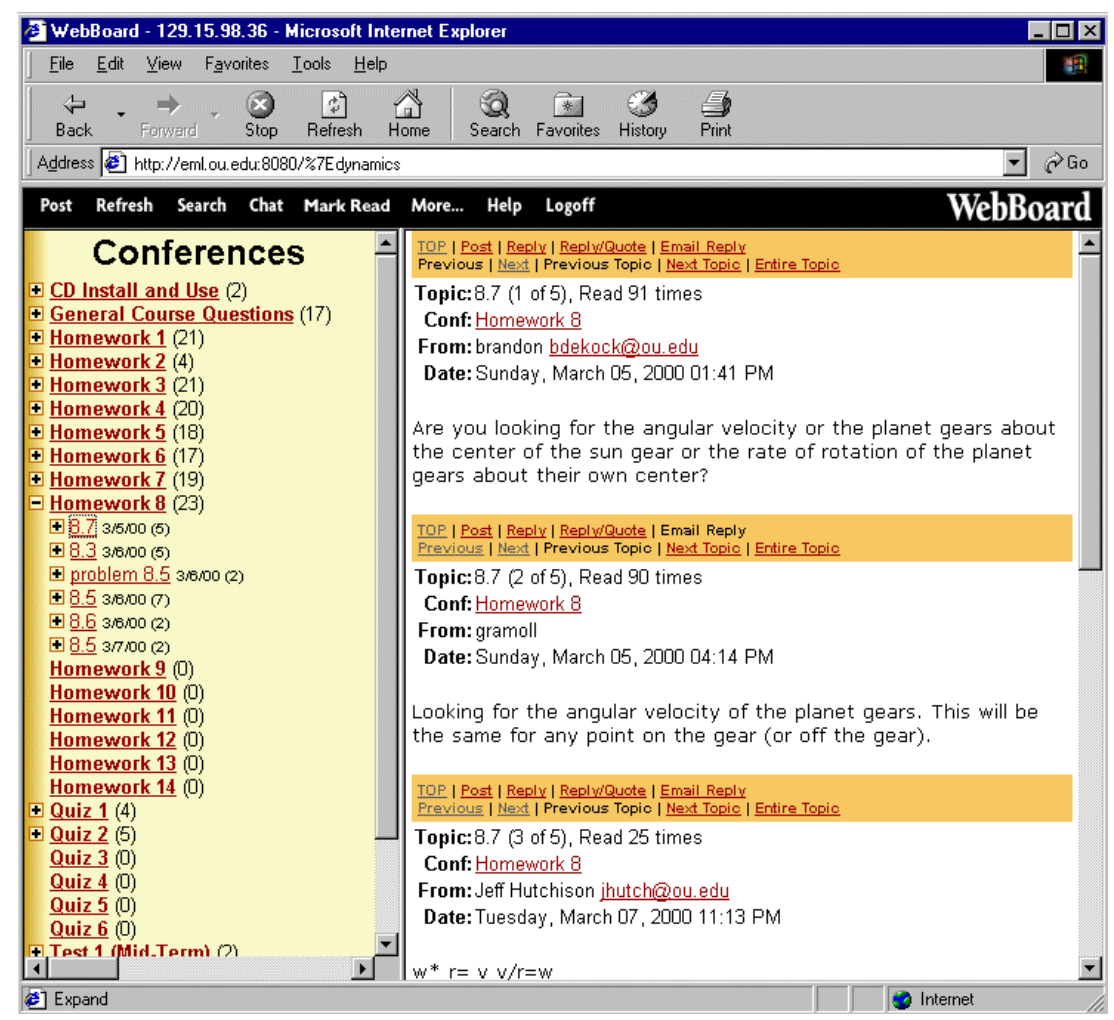

Fig. 5. Web Board Discussion on the Internet 
One of the main reasons for using Web Board was its ability to upload and view graphics. This allowed each student to modify a problem diagram (obtained from the web homework) and then post it with his or her question. Another feature that was useful during quizzes was the chat room where live discussions or announcements could be made. In the future, the chat room could also be effective when there are hundreds of students in a given course or group of courses that would like to have live discussions about the course or homework. With only 70-80 students in the course described in the paper, there were never enough students at any given time to make the chat rooms work effectively.

The web board concept, while not new, is an extremely important component to the online courses. With the web board, questions and discussions can be done similar to the interaction that takes place in a normal classroom. In some respects, the web board discussions allowed more students to participate in asking questions since there was no time limit or peer pressure not to ask questions. It also allowed students to ask questions when the questions arose, irrespective of time. Over the course of the semester, it was found that the time saved from students not coming to the office during hours (there were still official office hours) was offset by the time spent on the web board answering questions. However, less time was spent answering the same question numerous times since others could view the question and answer. The end result was three to four times as many questions were answered.

\section{On-Demand-Lectures}

One of the disadvantages of online teaching is the lack of participation in the classroom. This can be partially overcome with the use of streaming video over the Internet of all class lectures and with online discussion groups that was discussed previously. This gives all students the same information that was discussed and presented in the classroom, including student questions and answers. Furthermore, online students can still interact through the use of email questions that can be answered and discussed in the next classroom meeting.

Convenience is probably the most important reason for allowing students to view the lectures online. Internet-based streaming video is delivered directly to the students' laptop computers at any time or location. The student can repeat the lecture if there is concept that he did not understand. This feature is more important than originally thought, because the freedom to repeat a lecture became the number one reason why students like the online course.

\section{Video Streaming}

The ability to view video over the Internet has improved tremendously over the last 2 years through the concept of streaming video. Basically, the user can view the first minutes of the video while the latter parts are still downloading which saves the student time. Various video recording and video compression techniques were tested and developed for this course, including QuickTime, NetShow (now ActiveMovie), Vivo and Real Player.

It was determined that QuickTime (Fig 6) retained most of the desired advantages, and also allowed user control of the play back location and allowed post-compression editing. QuickTime also streamlined the processing steps for compression. 


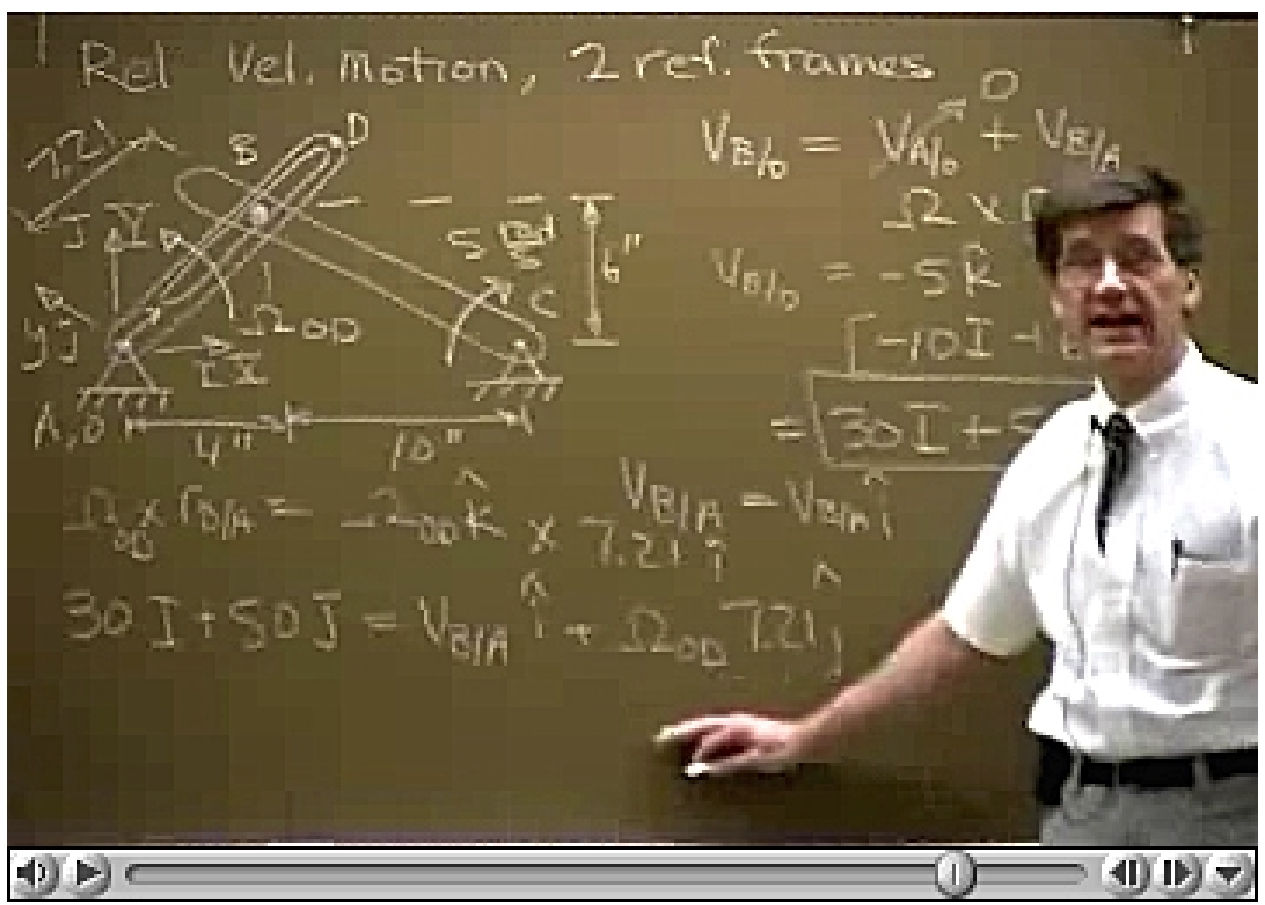

Fig. 6. QuickTime video format

With streaming video, the video must first be compressed (encoded) and then placed on a web server so that the user using a web browser that has a plug-in for that streaming video type could access it. The quality of the video when using the Sorenson codex that comes with QuickTime proved superior to NetShow, Vivo and RealPlayer. With Sorenson codex, it was possible to compress the video considerably and still retain high quality.

\section{Teaching Style for Online Lectures}

It is wrong to assume that any course can be simply video taped and then converted to streaming video. There are a number of critical issues that need to be address in the teaching style to maximize the benefit of the Internet-based video. Firstly, students need to have concepts introduced, taught and summarized into 10 or $15 \mathrm{~min}$. segments. To maximize the compression, it is important to minimize the change in motion on the screen. Thus the instructor should minimize walking around and learn to write within a preset area of the board of about $6 \times 4$ feet. Finally, the writing style needs to be neat and clear. The video will be able to record normal size writing but sloppy diagrams, text on top of other text, and cursive text will not be readable on the video.

In summary, the video over the Internet worked well for the Dynamics course. The students were able to access the video within 24 hours after the lecture was presented. The video was compressed to 100 kilobits per sec (kbs) at a resolution of 360 by 240 pixels and 10 frames per second. This is roughly twice the data rate of the common 56k modem, but was well within the wireless network connection of 150-200 kbs that the students use with their laptop computers. 


\section{Student Response}

The student responded favorably to the online course. Throughout the semester, the students took surveys for both the learning experience and the use of technology in teaching. In general, the students felt that they had a good educational experience. However, they did not feel that they had learned more material as compared to a traditionally taught course. They strongly agreed that the technology allowed then to maintain the course based on their own schedules and convenience. They enjoyed the element of flexibility, which was derived from the freedom to attend the class anywhere on campus that was added to their schedules.

The tests and homework were judged to be lengthy and hard, which is consistent to classroom type class. The class size of this course this semester allowed the author to quickly solve any problems that developed due to the use of technology. Some of the early problems included, installation problems of the CD-ROMs (correct version of QuickTime needed), wireless network connection, and variations of Internet browsers.

The students also gave high marks in the survey for taking advantage of technology in the classroom. Since all the students had laptop computers, they were eager and even appreciative to have the chance to finally use them for a complete course. The students did make several useful comments about the technology, such as suggesting sliders on the videos and requesting simple web-based utilities. Both of these comments were implemented for later class.

\section{Summary}

Over the one semester, Dynamics was taught using only electronic media by the author at the University of Oklahoma in the School of Aerospace and Mechanical Engineering. The electronic media included a courseware CD-ROM for the main content, lectures over the Internet, homework assigned and submitted online, web boards for group discussions, online quizzes and a general web site for course information. No printed textbook was used for the course. The students were able to learn the material as effectively as students using the traditional teaching method using print media but had the added flexibility to obtain information in or out of the classroom. The student comments consistently praised the new teaching method and enjoyed the elements of freedom and flexibility. The main complaint from students was the time oriented testing which put pressure on them to know the material concisely.

Since the course was delivered over the Intranet at the University of Oklahoma, all students had laptop computers and were connected to the network through wireless network cards that attached to their computers. The wireless connections allowed all lectures to be broadcast over the Internet and minimized the need for the student to attend the actual class. Through experimentation it was found that QuickTime delivered the best quality video, for streaming video lectures with the smallest bandwidth.

From the instructor point of view, the course took enormous amounts of time to develop all new electronic homework problems and quizzes. In addition, a backend grading system and online testing routines were developed using server-based CGI-Perl scripts. However the benefits of the online homework management system could be experienced from the beginning of the course. 
For just one or two class, the time spent cannot be justified, but if the system can be used for multiple courses over a number of years, then the time and effort can be justified. The end goal would be to create an e-course curriculum with a set of multiple electronic courses that can be

offered either online or in-class to help address the scheduling and learning needs of the student.

\section{References}

1. Brooks, D. W. Web-Teaching A guide to Designing Interactive Teaching for the World Wide Web, Plenum Press, New York, 1997

2. Regan, M. and S. D. Sheppard, "Interactive Multimedia Courseware and Hands-on Learning Experience: An Assessment Study," ASEE Journal of Engineering Education, 199685 (2), p 123-130.

3. Gramoll, K.C., R.F. Abbanat, and K. Slater, "Interactive Multimedia for Engineering Dynamics," ASEE 1996 Conf. Proc., Washington, D.C., June 1996.

4. Gramoll, K.C., R. Abbanat and K. Slater, Multimedia Engineering Dynamics, AddisonWesley, (1997).

5. Flori, R. E., M. A. Koen, and D.B. Oglesby, Basic Engineering Software for Teaching Dynamics, ADEE Journal of Engineering Education, 1996, p 61-67.

6. Lam, H. S. and K. C. Gramoll, 1999 "Practical Streaming Video on the Internet for Engineering Courses On- and Off-Campus," Proceedings of the ASEE Annual Conference, Charlotte, N. C., June 1999.

7. Kroll, L., "Good Morning, HAL," Forbes, March 8, 1999, p 118-120.

Biography

\section{YELLAMRAJU VIKAS}

Yellamraju Vikas is currently a graduate student in Industrial Engineering at the University of Oklahoma. He completed his B.Tech. in Mechanical Engineering in spring of 1995 at Nagarjuna University, India. He worked as a Maintenance Engineer for 3 years in Polyester/Nylon Monofilament Yarn plant in India before starting his graduate program in U.S. His present work involves research on multimedia technology for engineering application.

\section{TONY ROMANELLO}

Tony Romanello is currently a graduate student at the University of Oklahoma. He completed his B.S. of Mechanical Engineering in spring of 1999 with distinction at the University of Oklahoma. He focused on multimedia engineering and distance learning with his graduate-level research through fall of 1999.

\section{KURT GRAMOLL}

Kurt Gramoll is the Hughes Centennial Professor of Engineering and Director of the Engineering Media Lab at the University of Oklahoma. He has developed and published CDs and web-based sites for engineering education, K-12 instruction, and training in industry. He has started two multimedia companies for the development and distribution of technical electronic media. Dr. Gramoll received his B.S. degree in Civil engineering and M.S. degree in Mechanical Engineering, both from the University of Utah. He received his Ph.D. in Engineering Science and Mechanics from Virginia Tech. Previously, he has taught at the Univ. of Memphis and Georgia Tech. 